\title{
INTERNATIONAL JOURNAL OF PHILOSOPHY
}

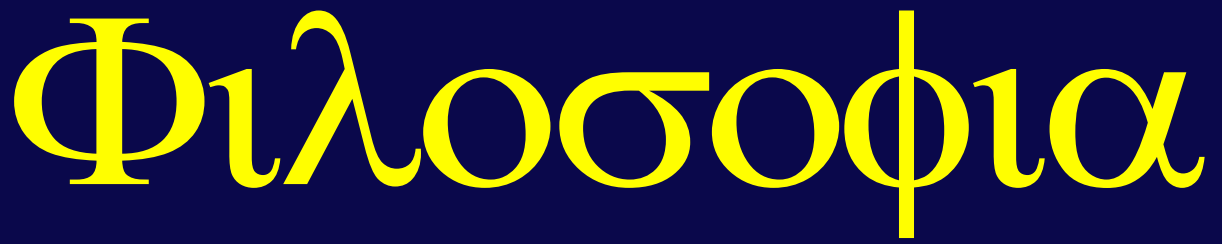

VOLUME 21

Philosophia (Philippines)

SPECIAL ISSUE

SPECIAL COMMEMORATIVE ISSUE CENTENNIAL ANNIVERSARY OF GST. JOEN PAUL II

CELEBRATING THE

LIFE AND

THOUGHTS OF

JOHN PAUL II:

THE MAN AND

SAINT WHO

TRANSFORMED THE

MODERN WORLD

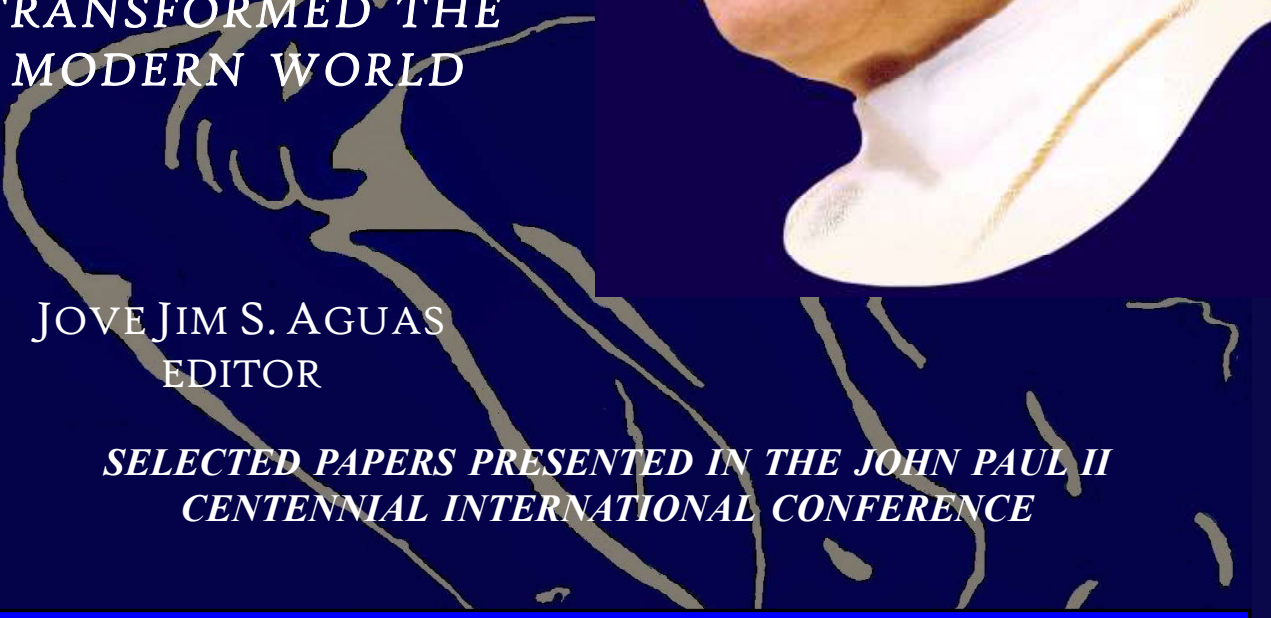

Philippine National Philosophical Research Society

[www.pnprs-philosophia.com]

John Paul II Society of the Philippines

https://ejournals.ph/issue.php?id=1150 


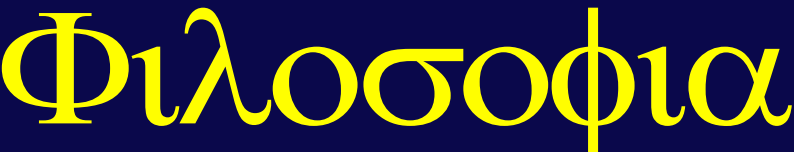

VOLUME 21, SPECIAL ISSUE 2020

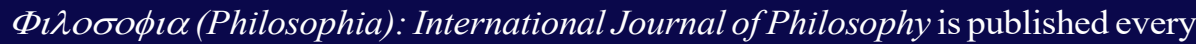
January and June of each year. Manuscripts submitted for publication in the journal must be sent to the Editor, Philosophia, via email attachment (philosophiaeditor@gmail.com). Manuscripts are double-blind refereed. To view samples of the journal, please visit http:// www.pnprs-philosophia.com.

References and bibliography should utilize standard parenthetical references (PR) and reference lists (RL). This may be done in accord with the specifications given in the seventh edition of Kate Turabian's A manual for writers. Those submissions not in accord with this documentation convention may be returned to the authors for revisions prior to sending to the readers. The editor, associate editor, and book review editor reserve the right to make editorial modifications.

Authors are responsible for the accuracy of all quotations and for providing complete references. An abstract of not more than one hundred words, summarizing the thesis or intent of the article, should be appended along with the brief curriculum vitae of the author. Contributors should keep their own copies of all materials submitted. They should also include their respective email and exact mailing addresses. For multiple submissions, only one paper will be published every year. The medium of expression of the journal is English-American or British. Only the letters of the British-American alphabet, including the Spanish-Filipino n, will be accepted in the document text.

Authors of published articles in this journal are entitled to receive a copy of their respective published papers. They are, however, enjoined to become members of the Philippine National Philosophical Research Society during the year their articles appear in the journal. Co-authors of an article will each pay the membership fee.

Foreign annual subscription rate (including mailing and handling) is US\$120.00 for libraries and institutions. Local annual subscription rate for libraries and institutions is PHP1,700. Annual foreign individual membership to the Philippine National Philosophical Research Society is US\$85.00 (including mailing and handling) while local membership fee is PHP1,000.00. Checks should be made payable to the Philippine National Philosophical Research Society, c/o The Philosophia Editor, \#79 North Circle St., Country Homes Subdivision, Cainta, Rizal 1900, Philippines. Or one can pay through the bank, moneygram, Paypal, or the Western Union.

$\Phi \imath \lambda \circ \sigma o \phi \imath \alpha$ is indexed in the Clarivate Analytics Master Journal List (formerly Thomson Reuters), Scopus, Arts and Humanities Citation Index and The Philosopher's Index. It is included in the CARHUS Plus+2014, SJR. SCImago Journal \& Country Rank, Scopus Journal metrics, ASEANCitation Index Database, EBSCODatabase. The Philippine Commission on Higher Education (CHED) certified the journal as Category A-1 in 2012 and also awarded it with the Journal Incentive Program (JIP) Journal Challenge Grant in 2017. 